\title{
Prevalence of low birth weight in a scenario of economic depression in Argentina
}

\author{
Julia Ratowiecki, B.S. ${ }^{a, b}$, Fernando A. Poletta, PhD ${ }^{a, b, c}$, Lucas G. Giménez, PhD ${ }^{a, b}$, \\ Juan A. Gili, PhD ${ }^{a, b}$, Mariela S. Pawluk, PhD ${ }^{a, b}$ and Jorge S. López Camelo, PhDa,a,c
}

\begin{abstract}
Introduction. Low birth weight (LBW) is considered a general indicator of health because it is related to complications in the life of a newborn infant and is one of the leading causes of infant mortality. It is a multifactorial indicator, and its determinants include socioeconomic factors.

Objective. To assess the impact of economic inequality on the prevalence of LBW by quantifying its differential effect by maternal age, level of maternal education, and level of care. Population and methods. Epidemiological, cross-sectional study that analyzed all births occurred in Argentina between 2001 and 2013 based on data provided by the National Registry of births, corresponding to the Health Statistics and Information Department. The temporal variation in the prevalence of LBW newborn infants ( $<2500$ grams) and its relation to demographic and socioeconomic indicators were studied. Its association was assessed using logistic regression models.

Results. A total of 9001960 births were included. The prevalence of LBW newborn infants during the 2001 economic crisis increased $-6 \%$ in 2002 and $7 \%$ in 2003- The impact was heterogeneous and higher on public hospitals $([\mathrm{PR}]=1.03)$ and adolescent mothers $(\mathrm{PR}=1.07)$, butno impact was observed on a low level of maternal education (PR=0.99).

Conclusions. The impact of socioeconomic inequality on the prevalence of LBW was significant and heterogeneous, especially on public hospitals and mothers at the extremes of maternal age.

Key words: low birth weight, socioeconomic factors, economic crisis, Argentina.
\end{abstract}

http: / / dx.doi.org/10.5546/ aap.2018.eng.322

Technological

Promotion, Ministry of

Science, Technology,

and Productive

Innovation. Main

Investigator: Jorge

S. López Camelo,

M.D. Reintegrantion

grant awarded by the

Research Board of

Clinical Research and

Medical Education

Center "Norberto

Quirno" (CEMIC) to

Julia Ratowiecki.

Conflict of interest:

None.

Received: 11-28-2017

Accepted: 4-10-2018

To cite: Ratowiecki J, Poletta FA, Giménez LG, et al. Prevalence of low birth weight in a scenario of economic depression in Argentina. Arch Argent Pediatr 2018;116(5):322-327.

\section{INTRODUCTION}

According to the World Health Organization, low birth weight (LBW) is the most important index to predict infant mortality, especially, neonatal mortality. The relation between LBW and several post-natal complications has been studied, such as acute respiratory infection and diarrhea in the first year of life, and neurological disorders and intellectual deficit, metabolic syndrome, diabetes, among others, in adult life. ${ }^{1,2}$

LBW is the result of fetal (intrauterine) growth restriction and / or a short gestational period. Therefore, LBW newborn infants may be term infants with low birth weight for gestational age or preterm infants with adequate birth weight for gestational age. LBW is multifactorial and its determinants include psychosocial stress, ${ }^{3}$ smoking, ${ }^{4}$ malnutrition, anemia ${ }^{5,6}$ and extreme maternal age. ${ }^{2}$

There is ample bibliography establishing a relation between adverse socioeconomic conditions and unfavorable reproductive health outcomes. ${ }^{7-10}$ Adverse socioeconomic conditions account for complex challenges. For example, economic crises, that typically involve a rise in poverty and unemployment. Crises have consequences on the population at large, and their effects differ considerably among social sectors and affect education, nutrition, and self-care individually.

A renowned economic crisis took place in Argentina by the end of 2001. It led to poverty levels affecting $54 \%$ of the population, destitution levels that reached $25 \%$, and unemployment, which rose to almost $26 \%$; this resulted in a socioeconomic inequality with the worst income distribution in the past 30 years. ${ }^{11}$ Specifically in relation to health, it increased stress, emerging diseases, and mortality. ${ }^{12}$

The working hypothesis is that there should be an association between the economic crisis of 2001, as 
an indicator of adverse socioeconomic conditions, and LBW. The objective of this study was to assess the impact of economic inequality on the prevalence of LBW by quantifying its differential effect by maternal age, level of maternal education, and level of care.

\section{POPULATION AND METHODS}

This was an epidemiological, cross-sectional study. Data from the National Registry of births occurred in Argentina between January 2001 and December 2013 were used, provided by the Department of Health Statistics and Information. ${ }^{13}$ Stillbirths, live births with a birth weight of less than 500 grams, and infants whose weight was not recorded were excluded.

The dependent outcome measure was the annual prevalence of LBW newborn infants. Based on the definition by the World Health Organization, LBW was defined as a birth weight of less than 2500 grams. Independent outcome measures included the analysis of gross domestic product (GDP) as provided by the World Bank, ${ }^{14}$ time (in years), and demographic outcome measures categorized as follows:

- Maternal age: level 1 (11 to 19 years old), level 2

(20 to 29 years old), level 3 (30 to 45 years old), and level 4 (46 to 59 years old). Mothers aged 2029 years old were taken as the reference.

- Level of maternal education: level 1 (incomplete primary education or less), level 2 (complete primary education or incomplete secondary education), and level 3 (complete secondary education, complete or incomplete university education). The intermediate level was taken as the reference: complete primary education or incomplete secondary education.

- Level of care: a birth taking place in a public (level 0) or private hospital (level 1). Births occurring in private hospitals were taken as the reference.

The population prevalence of LBW newborn infants was estimated, and Pearson's correlation was calculated using the corresponding GDP. In addition, the prevalence of LBW was analyzed as stratified by demographic outcome measures. Then, LBW was analyzed based on year, maternal age, level of maternal education, and level of care using a multiple logistic regression model (E1). The corresponding odds ratios were obtained and, using the conversion (E2) proposed by Zocchetti et al., ${ }^{15}$ transformed to prevalence ratios (PRs), which were analyzed to identify the association among outcome measures.
$P\{Y=1 / A, X, R\}=1 /(1+e z)-g ~ Z=\log (y)(E 1)$

Where $Z=a+\sum b i A i+\sum c i X i+\varepsilon$

$\mathrm{Y}=$ birth weight in grams (dependent outcome measure).

$\mathrm{A} \mathbf{i}=$ year of birth.

$\mathrm{X} \mathrm{i}=$ demographic outcome measures (independent outcome measure)

bi, ci, and di $=$ coefficients.

$\varepsilon=$ residual error (variability not accounted for by the other model terms).

$$
\mathrm{PR}=\frac{\mathrm{OR}}{\left(1+p_{\mathrm{x}}[\mathrm{OR}-1]\right)}
$$

$p_{x}$ is the prevalence of disease (low weight) in the reference group; $\mathrm{OR}=$ odds ratio.

In order to measure the crisis' differential impact, the prevalence of LBW newborn infants corresponding to the crisis period (from January 2002 to December 2003) and the non-crisis period (from January 2001 to December 2001 and from January 2004 to December 2013) were determined and the relative increase ( $\left.{ }^{*} \mathrm{RI}\right)$ was estimated within each level of the studied demographic outcome measures.

$$
{ }^{*} \mathrm{RI}=\frac{\text { LBW crisis-LBW non-crisis }}{\text { LBW non-crisis }} \times 100
$$

Then, a multiple logistic regression (E3) was done with an interaction term on the health indicator comparing both periods (crisis and noncrisis) so as to identify the heterogeneity of the economic crisis impact:

$P\{Y=1 / A, X, R\}=1 /(1+e z)-g Z=\log (y)(E 3)$

Where $Z=a+\sum b i X i+c i C+e i C^{*} \sum b i X i+\varepsilon$

$\mathrm{Y}=$ birth weight in grams (dependent outcome measure).

$X \mathrm{i}=$ demographic outcome measures (independent outcome measure).

bi, ci, di, and ei $=$ coefficients.

$\mathrm{C}=$ crisis.

$\mathrm{eiC}^{\star} \sum \mathrm{biXi}=$ interaction term.

$\varepsilon=$ residual error (variability not accounted for by the other model terms).

Given that, in this study, we included all births occurred in Argentina in the January 2001-December 2013 period, the interpretation of results was based on the size of the differences observed in the regression models and not on the $p$ values associated with each coefficient because there was no statistical inference. 
The Stata 12.0 and Microsoft Excel software programs were used for the study.

\section{RESULTS}

\section{Argentine population}

This study included 9001960 live births occurred in Argentina in the January 2001-December 2013 period.

The highest prevalence values for LBW newborn infants were observed in 2002 and 2003, with an increase of $6 \%$ and $7 \%$ from 2001, respectively (Table 1). As of 2004, a fall and subsequent recovery was observed.

In addition, in 2002, the GDP fell $(64 \%)$ and increased progressively in the following years. The Pearson's correlation between GDP and the frequency of LBW newborn infants was negative $(\mathrm{r}=-0.69)$, which may also be seen in Figure 1.

\section{Demographic outcome measures}

The prevalence of LBW newborn infants in 2002 was observed to increase in all groups. However, differences were noted among them (Table 2). The mothers at the extremes of maternal age (adolescents or older than 30 years) had higher prevalence values of LBW newborn infants than those who were 20-29 years taken as reference. In relation to the level of maternal education, mothers with a higher level had lower prevalence values of LBW newborn infants. The prevalence was higher in public hospitals than in private ones. A higher prevalence of LBW

TABLE 1. Relation between the prevalence of low birth weight newborn infants and gross domestic product during the 2001-2013 period in Argentina

\begin{tabular}{lccccc}
\hline Year & Births & LBW births & \% of LBW & GDP [billion USD] & GDP relative to 2001 \\
\hline 2001 & 635669 & 48334 & 7.60 & 2.69 & 1.00 \\
2002 & 654578 & 52582 & 8.03 & 0.98 & 0.36 \\
2003 & 664938 & 54139 & 8.14 & 1.28 & 0.47 \\
2004 & 690317 & 52918 & 7.67 & 1.82 & 0.68 \\
2005 & 682763 & 50064 & 7.33 & 2.21 & 0.82 \\
2006 & 679831 & 49482 & 7.28 & 2.63 & 0.98 \\
2007 & 679037 & 49274 & 7.26 & 3.29 & 1.06 \\
2008 & 721703 & 53010 & 7.35 & 4.04 & 1.03 \\
2009 & 719695 & 51711 & 7.19 & 3.77 & 0.99 \\
2010 & 731591 & 53315 & 7.29 & 4.62 & 0.99 \\
2011 & 728064 & 52688 & 7.24 & 5.58 & 1.40 \\
2012 & 727489 & 52813 & 7.26 & 6.04 & 1.72 \\
2013 & 686285 & 50727 & 7.39 & 2.24 & 2.08 \\
Total & $\mathbf{9 0 0 1 9 6 0}$ & $\mathbf{6 7 1 0 5 7}$ & & & 0.99 \\
\hline
\end{tabular}

LBW: low birth weight; GDP: gross domestic product; PR: prevalence ratio [ $p=$ prevalence in 2001 (0.076)]; REF: reference.

FIGURE 1. Relation between the prevalence of low birth weight newborn infants and gross domestic product relative to $2001 \mathrm{in}$ Argentina

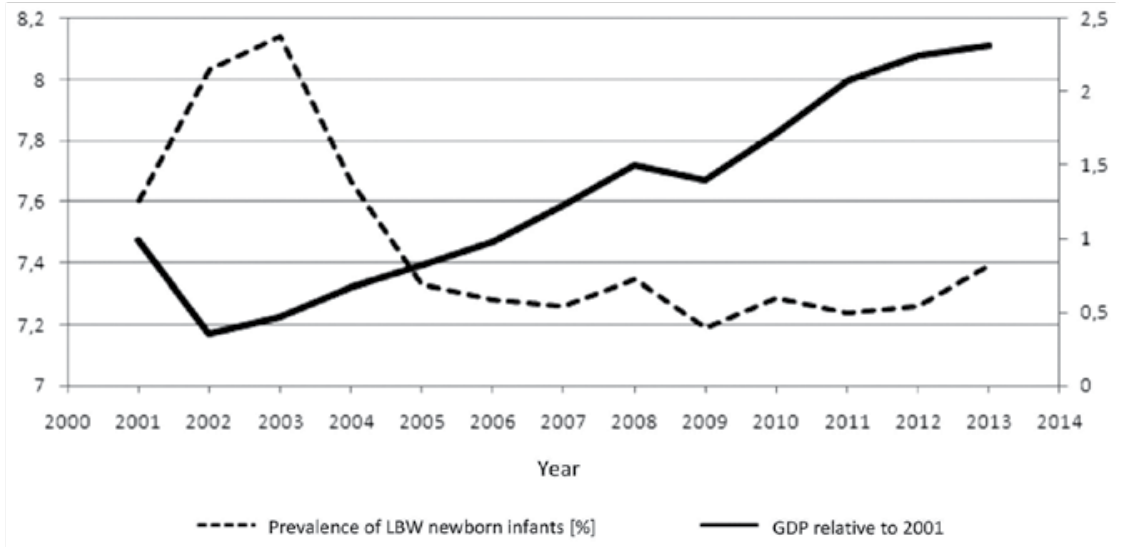

LBW: low birth weight; GDP: gross domestic product. 
newborn infants was observed in public hospitals and among mothers who were adolescents or older than 30 years old.

\section{Differential impact of the crisis}

The relative increase in the crisis period compared to the non-crisis period was different in each group (Table 3 ). In relation to maternal age, the higher increase was observed in the group of adolescent mothers, whereas the lower one was noted among those older than 45 years. Among the different levels of maternal education, the lower impact was observed among those with a higher education level, and the increase was higher in public hospitals than in private facilities (Annex).

\section{DISCUSSION}

The objective of this study was to analyze the impact of adverse socioeconomic conditions on LBW. The underlying hypothesis is that LBW is susceptible to environmental changes resulting from a lack of nutritional resources and antenatal care, and structural deficiencies in health care services resulting from social inequalities. To this end, we used a direct and objective indicator such as the Argentine crisis of 2001 to avoid using poverty indices that are developed by combining different types of outcome measures, which are then difficult to interpret.

GDP allowed to see the fall of the domestic economy during the economic crisis of 2001. The

TABLE 2. Percent prevalence of low birth weight newborn infants between 2001 and 2013 in Argentina stratified by demographic outcome measures

\begin{tabular}{|c|c|c|c|c|c|c|c|c|c|}
\hline \multirow[t]{2}{*}{ Year } & \multicolumn{4}{|c|}{ Maternal age (years old) } & \multicolumn{3}{|c|}{ Level of maternal education* } & \multicolumn{2}{|c|}{ Level of care } \\
\hline & 11-19 & 20-29 & $30-45$ & 46-59 & Level 1 & Level 2 & Level 3 & Public & Private \\
\hline 2001 & 9.67 & 7.01 & 7.59 & 10.31 & 7.95 & 7.92 & 6.88 & 7.51 & 6.46 \\
\hline 2002 & 10.28 & 7.37 & 8.03 & 13.25 & 8.38 & 8.35 & 7.34 & 7.97 & 6.69 \\
\hline 2003 & 10.43 & 7.54 & 8.08 & 14.57 & 8.50 & 8.46 & 7.50 & 8.02 & 6.95 \\
\hline 2004 & 9.71 & 6.98 & 7.79 & 13.68 & 7.78 & 8.00 & 7.10 & 7.80 & 6.68 \\
\hline 2005 & 8.95 & 6.61 & 7.61 & 13.93 & 7.42 & 7.60 & 6.90 & 7.68 & 6.71 \\
\hline 2006 & 8.75 & 6.62 & 7.53 & 12.10 & 7.19 & 7.55 & 6.91 & 7.65 & 6.71 \\
\hline 2007 & 8.61 & 6.57 & 7.60 & 14.95 & 7.55 & 7.51 & 6.86 & 7.67 & 6.66 \\
\hline 2008 & 8.66 & 6.66 & 7.66 & 15.73 & 7.73 & 7.54 & 7.01 & 7.79 & 6.76 \\
\hline 2009 & 8.53 & 6.46 & 7.53 & 14.18 & 7.51 & 7.38 & 6.85 & 7.57 & 6.67 \\
\hline 2010 & 8.45 & 6.51 & 7.75 & 17.30 & 7.56 & 7.47 & 7.02 & 7.59 & 6.89 \\
\hline 2011 & 8.35 & 6.46 & 7.72 & 18.93 & 7.36 & 7.35 & 7.05 & 7.50 & 6.90 \\
\hline 2012 & 8.41 & 6.48 & 7.72 & 17.52 & 7.41 & 7.40 & 7.04 & 7.56 & 6.84 \\
\hline 2013 & 8.62 & 6.63 & 7.79 & 20.16 & 7.58 & 7.55 & 7.18 & 7.67 & 7.00 \\
\hline Total & 8.98 & 6.76 & 7.72 & 15.24 & 7.72 & 7.70 & 7.04 & 7.68 & 6.78 \\
\hline
\end{tabular}

* Classification of maternal education. Level 1: incomplete primary education or less. Level 2: complete primary education or incomplete secondary education. Level 3: complete secondary education, complete or incomplete university education.

TABLE 3. Percentage of low birth weight newborn infants during the crisis and the non-crisis periods, stratified by demographic outcome measures

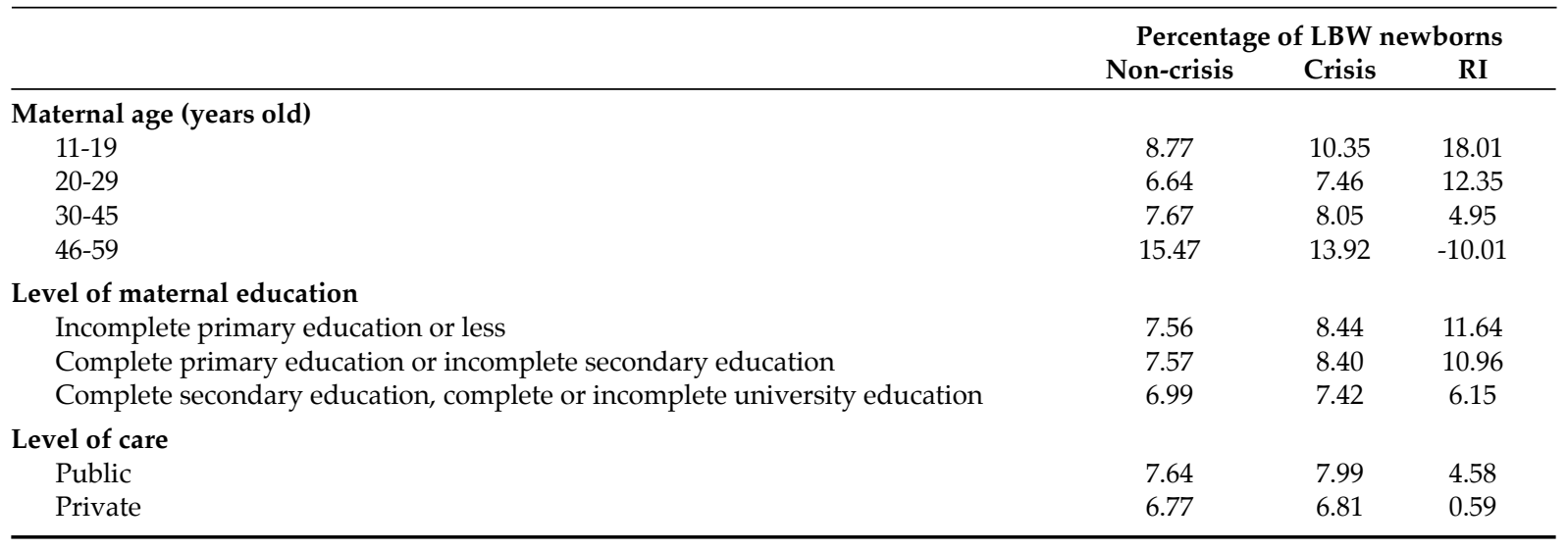

LBW: low birth weight; RI: relative increase. 
analysis of the correlation between the economic and health indicators showed an evident association between the reduction of the GDP and the increase of the prevalence of LBW newborn infants. This means that there was a reverse association between the economic situation and health, thus supporting the hypothesis that LBW was related to socioeconomic determinants. This confirms that the crisis period (January 2002-December 2003) is an indicator of adverse socioeconomic conditions to define exposure.

An increase in the prevalence of LBW newborn infants was observed after the economic crisis of 2001, as in Spain, where the prevalence of LBW newborn infants increased more markedly during the worst part of their economic crisis (20092010). ${ }^{16}$ The same has been seen in Iceland, ${ }^{17}$ where the prevalence of LBW newborn infants increased after the economic collapse of 2008 compared to the preceding period.

To understand the impact of the economic crisis on LBW, it should be noted that if approximately 690000 children are born each year across the country, a $0.5 \%$ increase in the prevalence of LBW newborn infants -as seen in the Argentine population between 2001 and 2002corresponds to approximately 3450 newborn infants whose LBW could have been prevented.

As per our analysis, the impact of the economic crisis on LBW was heterogeneous among the different maternal age groups and levels of maternal care.

During the studied period, the prevalence of LBW newborn infants was higher in public hospitals than in private facilities. During the crisis period, the number of LBW newborn infants increased in both levels of care, although the impact was higher in public hospitals. These outcomes are consistent with other studies that associated an unfavorable socioeconomic level with health problems. ${ }^{7}$ Other studies have demonstrated the relation between LBW and tobacco and alcohol use and the number of antenatal care visits. ${ }^{18}$ Whereas this study did not include these outcome measures separately, in Argentina, the population who attends public hospitals in general has a lower income and less favorable life conditions, a higher tobacco and alcohol use, and fewer antenatal care visits. ${ }^{19}$

Mothers at the extremes of maternal age had a higher prevalence of LBW newborn infants. On the one side, mothers who were 11-19 years old evidenced a bigger impact by the economic crisis. This is consistent with other studies ${ }^{2,20}$ that associated LBW with biological immaturity, such as restricted growth and development, and psychosocial factors, such as unintended pregnancy, single mother, family neglect, and few or no antenatal care visits. ${ }^{21}$ On the other reproductive age extreme, a higher prevalence of LBW was observed among mothers older than 30 years, although the impact of the economic crisis on this group was lower. The association with elderly mothers is consistent with a study that determined a higher risk for mothers older than 40 years compared to those aged 20-34 years, and associated it with pregestational and gestational conditions. $^{22}$

It is worth noting that many studies have reported an association between a low level of education and a higher LBW incidence. ${ }^{4,23}$ The same tendency has been observed based on our outcomes, although the magnitude of the differences were small.

\section{Strengths}

On the one side, this study included all births occurred in Argentina between January 2001 and December 2013, and more than nine million births were analyzed. On the other side, we used the economic crisis as a response indicator so it was not necessary to create other indices. The tool selected for this study is highly sensitive and poorly specific because, although it does not indicate which poverty outcome measures affect LBW to a greater extent, it includes all those that cannot be measured when developing a socioeconomic index.

\section{Study limitations}

Births occurring before 2001 were not provided, although it would have been beneficial to have such information in order to understand the variation in the prevalence of LBW newborn infants prior to the economic crisis.

Another limitation is the bias known as "ecological fallacy" to which all cross-sectional/ ecological studies are exposed, i.e., individual inferences based on group pooled data.

Gestational age was not registered in more than $15 \%$ of births, so it was not possible to analyze the difference between preterm and term newborn infants. Considering that it has been demonstrated that more than half of LBW newborn infants are born prematurely, ${ }^{24}$ it would have been interesting to include this outcome measure in our analysis. However, the objective of this study was to analyze the association 
between unfavorable conditions and health, using LBW as an indicator without delving into the biological mechanisms involved.

This study did not include information on marital status, employment, number of antenatal care visits, birth interval, maternal disease or maternal tobacco or alcohol use separately. In the bibliography, these outcome measures are related to intrauterine growth disorders that may result in a LBW newborn infant. ${ }^{25,26}$

\section{CONCLUSION}

The effect of the socioeconomic inequality resulting from the 2001 crisis on the prevalence of LBW was heterogeneous across the Argentine population and had a bigger impact on public hospitals and mothers at the extremes of maternal age.

\section{REFERENCES}

1. Coronel Carvajal C, Rivera Lecha I. Peso bajo al nacer. Su influencia en la salud durante el primer año de vida. Rev Mex Pediatr 2003; 70(6):283-7.

2. Ticona Rendón M, Huanco Apaza D, TiconaVildoso M. Incidencia y factores de riesgo de bajo peso al nacer en población atendida en hospitales del Ministerio de Salud del Perú. Ginecol Obstet Mex 2012; 80(2):51-60.

3. Eriksson M, Räikkönen K, Eriksson JG. Early life stress and later health outcomes-findings from the Helsinki Birth Cohort Study. Am J Hum Biol 2014; 26(2):111-6.

4. Van den Berg G, van Eijsden M, Vrijkotte TG, et al. Educational inequalities in Perinatal outcomes: The mediating effect of smoking and environmental tobacco exposure. PLoS One 2012; 7(5):e37002.

5. DuanisNeyra N, Neyra Álvarez A. Factores que inciden en el bajo peso al nacer. Rev Cubana Enfermer 1998; 14(3):150-4.

6. Peraza Roque GJ, Pérez Delgado S, Figueroa Barreto Z. Factores asociados al bajo peso al nacer. Rev Cubana Med Gen Integr2001; 17(5):490-6.

7. Abu-Saad K, Fraser D. Maternal Nutrition and Birth Outcomes. Epidemiol Rev 2010; 32:5-25.

8. Nyarko KA, López-Camelo J, Castilla EE, et al. Explaining Racial Disparities in Infant Health in Brazil. Am J Public Health 2013; 103(9):1675-84.

9. Bozzoli C, Quintana-Domeque C. The weight of the crisis: evidence from newborns in Argentina. Rev Econ Stat 2014; 96(3):550-62.

10. Wehby GL, Giménez LG, López-Camelo JS. The Impact of Unemployment Cycles on Child and Maternal Health in
Argentina. Int J Public Health 2016; 62(2):197-207.

11. Susmel N. Argentina: Pobreza, desigualdad de oportunidades y políticas públicas. In: Albornoz V, Durán C, Fausto $\mathrm{M}$, et al. Pobreza, desigualdad de oportunidades y políticas públicas. Rio de Janeiro, Brasil: Konrad-Adenauer-Stiftung; 2012.Págs.8-19.

12. Zeballos JL. Argentina: efectos sociosanitarios de la crisis, 2001-2003. Buenos Aires: Organización Panamericana de la Salud; 2003.

13. Argentina. Dirección de Estadística e Información en Salud (DEIS). Ministerio de Salud. [Accessed on: April 26 ${ }^{\text {th }}, 2018$ ]. Available at:http: / / deis.msal.gov.ar.

14. Banco Mundial. Banco de datos. [Accessed on: April 26 ${ }^{\text {th }}$, 2018]. Available at http:/ / databank.bancomundial.org/ data/home.aspx.

15. Zocchetti C, Consonni D, Bertazzi PA. Relationship between prevalence rate ratios and odds ratios in cross-sectional studies. Int J Epidemiol 1997; 26(1):220-3.

16. Varea C, Terán JM, Bernis C, et al. Is the economic crisis affecting birth outcome in Spain? Evaluation of temporal trend in underweight at birth (2003-2012). Ann Hum Biol 2016; 43(2):169-82.

17. Eiríksdóttir VH, Ásgeirsdóttir TL, Bjarnadóttir RI, et al. Low birth weight, small for gestational age and preterm births before and after the economic collapse in Iceland: A population based cohort study. PLoS One 2013; 8(12):e80499.

18. Wehby G, Murray J, Castilla E, et al. Quantile effects of prenatal care utilization on birth weight in Argentina. Health Econ 2009; 18(11):1307-21.

19. Belizán J, Farnot U, Carroli G, et al. Antenatal care in developing countries. Paediatr Perinat Epidemiol 1998; 12(Suppl 2):1-3.

20. Pawluk MS. Condición socioeconómica adversa y defectos del desarrollo. Impacto de factores involucrados en la pobreza. [Dissertation]. Buenos Aires: UBA-FME; 2013.

21. Álvarez Fumero R, Urra Cobas LR, Aliño Santiago M. Repercusión de los Factores de Riesgo en el Bajo Peso al Nacer. RESUMED 2001; 14(3):117-24.

22. Donoso SE, Villarroel del P L. Edad materna avanzada y riesgo reproductivo. Rev Méd Chile 2003; 131(1):55-9.

23. Mortensen LH, Diderichsen F, Arntzen A, et al. Social inequality in fetal growth: a comparative study of Denmark, Finland, Norway and Sweden in the period 1981-2000. J Epidemiol Community Health 2008; 62(4):325-31.

24. Placek P. Maternal and infant health factors associated with low infant birth weight: Findings from the $1972 \mathrm{Na}$ tional Natality Survey. In Reed DM, Stanley FJ (eds.). The epidemiology of prematurity. Baltimore: Urban and Schwartzenberg; 1977.Pages 197-212.

25. Bortman M. Factores de riesgo de bajo peso al nacer. Rev Panam Salud Pública 1998; 3(5):314-21.

26. Leal Soliguera M. Comportamiento del bajo peso al nacer y repercusión sobre la mortalidad infantil en el quinquenio 2001-2005. Rev Cubana Obstet Ginecol 2009; 35(4):99-107. 


\begin{tabular}{lc}
\multicolumn{1}{c}{ ANNEX } \\
$\begin{array}{l}\text { TABLE S1. Logistic regression of the prevalence of low birth weight considering the levels of demographic outcome measures and } \\
\text { comparing the crisis and non-crisis periods }\end{array}$ \\
\hline \\
\hline \\
Outcome measure & PR \\
\hline CRISIS (2002-2003) & 1.05 \\
11-19-year-old mothers & 1.30 \\
CRISIS* 11-19-year-old mothers & 1.07 \\
20-29-year-old mothers & REF \\
CRISIS* 20-29-year-old mothers & REF \\
30-45-year-old mothers & 1.17 \\
CRISIS* 30-45-year-old mothers & 0.97 \\
46-59-year-old mothers & 2.42 \\
CRISIS* 46-59-year-old mothers & 0.86 \\
Mothers with incomplete primary education or less & 0.98 \\
CRISIS* Mothers with incomplete primary education or less & 0.99 \\
Mothers with complete primary education or incomplete secondary education & REF \\
CRISIS* Mothers with complete primary education or incomplete secondary education \\
Mothers with complete secondary education, complete or incomplete university education. \\
CRISIS* Mothers with complete secondary education, complete or incomplete university education. \\
Private hospitals & REF \\
CRISIS* Private hospitals & 0.99 \\
Public hospitals & 1.01 \\
CRISIS* Public hospitals & REF \\
Constant & REF \\
\hline
\end{tabular}

PR: prevalence ratio [ $p=$ prevalence in the non-crisis period (0.073)]; REF: reference.

A total of 7809741 cases were observed. Pseudo R2 $=0.0030$ and log-likelihood $=-2029706.7$. 